been found possible thus far to evolve a theory of mixtures sufficiently general in nature to include the case of systems in which one or both of the components are abnormal liquids. It is clear, however, that the theoretical isotherm must exhibit a maximum and a minimum in this region. In the figure, the broken line connecting the points $\mathrm{B}$ and $\mathrm{C}$ indicates such a form of the curve. It may be inferred, since the isotherms immediately above the critical end-point as well as in the homogeneous regions adjacent to the 3-phase equilibrium are comparatively flat, that the theoretical isotherm throughout the metastable and unstable regions will be comparatively flat.

\title{
Summary
}

1. The total vapor pressure of liquid mixtures of ammonia and metaxylene has been determined for the entire range of compositions at temperatures of $8^{\circ}, 10^{\circ}, 12^{\circ}, 14^{\circ}, 15^{\circ}, 17^{\circ}$ and $20^{\circ}$. Mixtures of liquid ammonia and metaxylene exhibit a critical end-point at $14.7^{\circ}$ at a pressure of 6.85 atmospheres and a composition of $81.4 \mathrm{~mol}$ per cent. of ammonia.

2. The composition of the liquid phases in equilibrium with each other in the 3-phase system has been determined at the temperatures given above and at $-33.5^{\circ}$. At lower temperatures the percentage of ammonia in the phase rich in xylene decreases very markedly with the temperature.

3 . The significance of the results obtained is briefly discussed.

WORCESTER, MassachusetTS

[Contribution from the Gates Chemical Laboratory of the California Institute of TECHNOLOGY, No. 14]

\section{THE COMPOSITION AND CRYSTAL STRUCTURE OF NICKEL NITRATE HEXAMMONIATE}

By RaLPH W. G. WYCKOFF ${ }^{1}$

Received March 24, 1922

\section{Introduction}

When an excess of ammonia is added to a concentrated solution of nickel nitrate in water, faintly blue isotropic octahedra are obtained to which have been assigned the composition $\mathrm{Ni}\left(\mathrm{NO}_{3}\right)_{2} .4 \mathrm{NH}_{3} .1$ (or 2) $\mathrm{H}_{2} \mathrm{O}$. By the slow cooling of a solution of appropriate concentration, large and perfect crystals of this salt are readily obtained. These crystals, however, decompose rapidly at room temperature, so that diffraction measurements were possible only after covering the crystal with a protecting coating of wax.

Comparison reflection spectra prepared in the usual manner ${ }^{2}$ from a

${ }^{1}$ Member of the Staff of the Geophysical Laboratory of the Carnegie Institution of Washington.

${ }^{2}$ Wyckoff, This Journal, 42, 1100 (1920). 
cleavage face of calcite (and of rock salt) and an octahedral face of one of these crystals, combined with its density, 1.46 as determined by a flotation-Westphal balance method, gave the following values of $\mathrm{m} / \mathrm{n}^{3}$, the ratio of the number $m$ of chemical molecules in the unit cell, to the cube of the order of the reflection $n$.

$$
\begin{aligned}
& m / n^{3}=4.34 \text {, if the composition is } \mathrm{Ni}\left(\mathrm{NO}_{3}\right)_{2} \cdot 4 \mathrm{NH}_{3}, \mathrm{H}_{2} \mathrm{O} \text {, } \\
& m / n^{3}=4.07 \text {, if the composition is } \mathrm{Ni}\left(\mathrm{NO}_{3}\right)_{2} \cdot 4 \mathrm{NH}_{3} \cdot 2 \mathrm{H}_{2} \mathrm{O} \text {. }
\end{aligned}
$$

The first of these values does not correspond to any integral number of chemical molecules within the unit cube; the second is, however, in sufficiently close agreement with the value $m=4$. It thus became evident that the first formula could not be a correct representation of the composition of these crystals. When, making the accustomed use of the results of the theory of space groups, ${ }^{3}$ a plausible structure containing 4 molecules of $\mathrm{Ni}\left(\mathrm{NO}_{3}\right)_{2} .4 \mathrm{NH}_{3} .2 \mathrm{H}_{2} \mathrm{O}$ within the unit was sought, it was found that none was possible. The incorrectness of the two assigned compositions of this salt, which thus became apparent, led to the following analyses.

\section{Analysis of the Nickel Nitrate Hexammoniate}

It was assumed that the crystals have the composition $\mathrm{Ni}\left(\mathrm{NO}_{3}\right)_{2}$.$x \mathrm{NH}_{3}, y \mathrm{H}_{2} \mathrm{O}$. Proceeding upon this basis two analyses were made: (1) a determination of the ammonia content, and (2) a determination of the amount of substance volatilized by ignition to nickel oxide (NiO). The amount of ammonia was obtained by adding a weighed portion of the salt directly to a known amount of standard hydrochloric acid solution and titrating back the excess of acid with standard alkali, using methyl red as indicator. The correctness of this direct titration was assured through comparison with an analysis by a Kjeldahl distillation.

The samples were prepared by the following procedure. The salt was precipitated as a fine powder by the addition of an excess of ammonium hydroxide to a cold conc. solution of nickel nitrate. This precipitate was collected, washed repeatedly and rapidly, inst with alcohol and then with ether, and kept in a refrigerated desiccator for at least 12 hours before weighing, in order that the salt might become free from ether. In this manner a constant weight was attained. After washing, the temperature of the salt was :at allowed to rise above $0^{\circ}$ until immediately before use.

Two determinations of the ammonia content gave $35.65 \%$ and $35.58 \%$ in the salt. The theoretical percentage for $\mathrm{Ni}\left(\mathrm{NO}_{3}\right)_{2} .6 \mathrm{NH}_{3}$ is $35.87 \%$.

Two determinations of the loss on igniting the salt to nickel oxide resulted as follows.

(1)

Wt. sample
G.
0.3719
0.2034

Wt. NiO

(i)

0.0977

0.0534
(3)

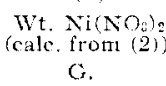

0.2390

0.1306

in $\mathrm{Ni}(\mathrm{NO}$
(4)

"Volatile matter"

(1) minus (3)

C.

0.1329

0.0728
(5)

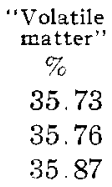

${ }^{3}$ Wyckoff, Am. J. Sci, 1, 127 (1921), etc. 
From these two sets of experiments it is clear that the true composition of these crystals is $\mathrm{Ni}\left(\mathrm{NO}_{3}\right)_{2} \cdot 6 \mathrm{NH}_{3}$.

\section{The Crystal Structure of the Nickel Nitrate Hexammoniate}

As already indicated, reflection spectra from the octahedral face showed that 4 molecules of $\mathrm{Ni}\left(\mathrm{NO}_{3}\right)_{2} .4 \mathrm{NH}_{3}, 2 \mathrm{H}_{2} \mathrm{O}$ could be associated with the unit cube. The molecular weights of ammonia and of water are nearly equal so that the same calculation shows that either 4 or 332 molecules of $\mathrm{Ni}\left(\mathrm{NO}_{3}\right)_{2} .6 \mathrm{NH}_{3}$ must be contained within the unit cell. With 4 molectles, the length of the side of this unit becomes $10.90 \AA$. L. $\left(10.96 \times 10^{-8} \mathrm{~cm}.\right)$.

The analysis of a series of Laue photographs with the incident X-rays roughly normal to octahedral faces and the subsequent determination of structure were carried out by methods already described. ${ }^{+}$

\section{TABLE I}

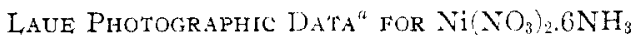

\begin{tabular}{|c|c|c|c|c|c|c|}
\hline \multicolumn{3}{|c|}{ Appearing planes } & \multirow[b]{2}{*}{$\begin{array}{l}\text { Istimated } \\
\text { intensity }\end{array}$} & \multicolumn{3}{|c|}{ Absent planes } \\
\hline $\begin{array}{l}\text { Indices of re- } \\
\text { tecting plane }\end{array}$ & $\begin{array}{l}\text { Relative } \\
\text { spacing }\end{array}$ & $\begin{array}{l}\text { Wave } \\
\text { length }\end{array}$ & & $\begin{array}{l}\text { Indices of re- } \\
\text { flecting platie }\end{array}$ & $\begin{array}{l}\text { Relative } \\
\text { pacing }\end{array}$ & $\begin{array}{l}\text { Wave } \\
\text { length }\end{array}$ \\
\hline $5 \overline{13}$ & 0.169 & $0 .+27$ & 10 & .50 & 0.156 & 0.498 \\
\hline 515 & $0.1+0$ & 0.397 & 7 & 425 & $0.1+9$ & $(0.475)$ \\
\hline 551 & $(0.1+0)$ & 0.376 & 6 & 362 & (1), 143 & 0,497 \\
\hline 355 & 0.130 & 0.429 & 7 & 461 & 0.137 & $0 .+22$ \\
\hline 553 & 0.130 & 0.458 & $7+$ & $16-1$ & 0.137 & 0.488 \\
\hline 137 & 0.130 & 0.440 & 2 & 525 & 0.136 & $(1 .+19$ \\
\hline $37 \overline{3}$ & 0.122 & 0.397 & 2 & 065 & 0.128 & 0.451 \\
\hline$\overline{175}$ & 0.115 & 0.386 & 2 & 560 & 0.128 & 0.358 \\
\hline 317 & 0.115 & 0.417 & $t$ & $7 \overline{14}$ & 0.123 & 0.438 \\
\hline 571 & $0.11 i$ & 0.323 & 0,5 & 274 & 0.120 & 0.390 \\
\hline 755 & 0.100 & 0.400 & 1 & +72 & 0.120 & 0.369 \\
\hline $1 \overline{5} 9$ & 0.096 & 0.430 & 0.5 & $71 \overline{6}$ & 0.1117 & 0.395 \\
\hline 915 & 0.096 & 0.400 & 0.1 & $\ldots$ & $\cdots$ & $\ldots$ \\
\hline $2 \overline{2} 1$ & 0.333 & 0.947 & 30 & $\ldots$ & $\ldots$ & $\cdots$ \\
\hline $1 \overline{2} 2$ & 0.333 & 0.828 & 8 & $\ldots$ & $\ldots$ & $\ldots$ \\
\hline $3 \overline{2} 0$ & 0.277 & 0.773 & 4 & $\cdots$ & $\ldots$ & $\ldots$ \\
\hline$\overline{3} 22$ & 0.242 & 0.771 & 2 & $\ldots$ & $\ldots$ & $\ldots$ \\
\hline $3 \overline{3} 2$ & 0.213 & 0.849 & 3 & $\ldots$ & $\ldots$ & $\ldots$ \\
\hline $4 \overline{3} 1$ & 0.196 & 0.770 & $0 . \overline{5}$ & $\ldots$ & $\ldots$ & $\ldots$ \\
\hline $5 \overline{12}$ & 0.182 & 0.865 & 0.1 & $\ldots$ & $\ldots$ & $\ldots$ \\
\hline$\overline{3} 50$ & 0.171 & 0.966 & 0.1 & $\ldots$ & $\ldots$ & $\ldots$ \\
\hline 433 & 0.171 & 0.773 & 0.5 & $\ldots$ & $\ldots$ & $\ldots$ \\
\hline
\end{tabular}

a Only typical data from a single photograph are recorded in this table. The estimated intensities are not to be considered as furnishing more than a general idea of the intensities of the various diffraction spots.

The characteristics of the Laue photographs furnished by this salt are almost identical with those given by the photographs from the hexammo-

4 Wyckoff, Am. J. Sci., 50, 317 (1920). Wyckoff and Posnjak, Thrs Journal., 43,2292 (1921). 
niates of the nickel halides. ${ }^{5}$ No planes were found to reflect in the first order region except those having all odd indices. Furthermore, the intensity peculiarities of these all odd planes closely resemble those of the halides. The nature of the data obtained from these photographs will be seen from Table $I$. In the double endeavor to increase the number of reflections found in the Laue photographs and particularly to bring out spcts in the first order having other than all odd indices, exposures three to four times as long as usual were made; but for the first purpose these long exposures had little success, and in the second regard they failed utterly.

In order to preserve the existence of $\mathrm{NH}_{3}$ as a distinct grouping of atoms, it was necessary to assign the hexammoniate halides ${ }^{5}$ to the paramorphic hemihedry (pyritohedral class) of the cubic system. The same is true for this salt. It is thus apparent that this crystal must have the symmetry of one of the three paramorphic space groups permitting 4 molecules within the unit cube, $\mathrm{T}_{\mathrm{h}}{ }^{2}, \mathrm{~T}_{\mathrm{h}}{ }^{3}$ and $\mathrm{T}_{\mathrm{h}}{ }^{6}$. Methods are at hand for distinguishing among these three space groups on the basis of the Laue photographic data to which they give rise, as will be shown in detail in a subsequent publication. These methods are applicable to the present case because there are 24 oxygen atoms and because the first and last of these space groups, being built upon a simple cubic lattice, have 24 as the maximum number of equivalent positions within the unit cell. The fact that only all odd planes are found in the first order would assign this crystal to $\mathrm{T}_{\mathrm{h}}{ }^{3}$, the space group corresponding to the hexammoniate halides. As reference to this previous work will show, the arrangement of the atoms in $\mathrm{Ni}\left(\mathrm{NO}_{3}\right)_{2} .6 \mathrm{NH}_{3}$ would then have to be as follows: Nickel, arrangement 4(b); Nitrogen (nitrate), 8(e); Nitrogen (ammonia), 24 (c); Oxygen, 24 (a) or 24 (c) with a value of $u$ different from that of the ammonia nitrogen atcms; Hydrogen, one grouping of atoms at 24(c) with a still different value of $u$, and one grouping of 48 equivalent atoms.

Both of these possible positions for the oxygen atoms not only require that the distance between nitrate nitrogen atoms and oxygen atoms should be very much greater than the corresponding distance found in sodium nitrate ${ }^{6}{ }^{6}$ but they also destroy the nitrate group itself. In view of these surprising results it seems desirable to see whether special values cannot be given to the coördinate positions of atoms in either $T_{h}{ }^{2}$ or $T_{b}{ }^{6}$ which permit the arrangements thus resulting likewise to conform with the diffraction data. By following an orderly procedure it can be shown that, though $\mathrm{T}_{\mathrm{h}}{ }^{2}$ cannot be made to approach a face-centered structure, appropriate coördinate values can be found for the space group $T_{h}{ }^{6}$.

\footnotetext{
${ }^{5}$ Ralph W. G. Wyckoff, This Journal, 44, 1239 (1922).

${ }^{6}$ W. I. Bragg, Proc. Roy. Soc., 89A, 468 (1911). Wyckoff, Phys. Rev., [2] 16, $149(1920)$.
} 
The most generally placed equivalent positions of $T_{\mathrm{h}}{ }^{6}$ are as follows. ${ }^{7}$

Twenty-four equivalent positions within the unit:

$$
\begin{aligned}
& \mathrm{xyz} ; \mathrm{x}+\frac{1}{2}, \frac{1}{2}-\mathrm{y}, \overline{\mathrm{z}} ; \overline{\mathrm{x}}, \mathrm{y}+\frac{1}{2}, \frac{1}{2}-\mathrm{z} ; \frac{1}{2}-\mathrm{x}, \overline{\mathrm{y}}, \mathrm{z}+\frac{1}{2} ; \\
& \mathrm{zxy} ; \overline{\mathrm{z}}, \mathrm{x}+\frac{1}{2}, \frac{1}{2}-\mathrm{y} ; \frac{1}{2}-\mathrm{z}, \overline{\mathrm{x}} \mathrm{y}+\frac{1}{2} ; \mathrm{z}+\frac{1}{2}, \frac{1}{2}-\mathrm{x}, \overline{\mathrm{y}} ; \\
& \mathrm{yzx} ; \frac{1}{2}-\mathrm{y}, \mathrm{z}, \mathrm{x}+\frac{1}{2} ; \mathrm{y}+\frac{1}{2}, \frac{1}{2}-\mathrm{z}, \mathrm{x} ; \mathrm{y}, \mathrm{z}+\frac{1}{2}, \frac{1}{2}-\mathrm{x} ; \\
& \overline{\mathrm{xyz}} ; \frac{1}{2}-\mathrm{x}, \mathrm{y}+\frac{1}{2}, \mathrm{z} ; \mathrm{x}, \frac{1}{2}-\mathrm{y}, \mathrm{z}+\frac{1}{2} ; \mathrm{x}+\frac{1}{2}, \mathrm{y}, \frac{1}{2}-\mathrm{z} ; \\
& \overline{\mathrm{zxy}} ; \mathrm{z}, \frac{1}{2}-\mathrm{x}, \mathrm{y}+\frac{1}{2} ; \mathrm{z}+\frac{1}{2}, \mathrm{x}, \frac{1}{2}-\mathrm{y} ; \frac{1}{2}-\mathrm{z}, \mathrm{x}+\frac{1}{2}, \mathrm{y} ; \\
& \overline{\mathrm{yzx}} ; \mathrm{y}+\frac{1}{2}, \mathrm{z}, \frac{1}{2}-\mathrm{x} ; \frac{1}{2}-\mathrm{y}, \mathrm{z}+\frac{1}{2}, \mathrm{x} ; \mathrm{y}, \frac{1}{2}-\mathrm{z}, \mathrm{x}+\frac{1}{2} .
\end{aligned}
$$

The following special positions reduce the number of equivalent positions.

Eight equivalent positions:

$8(\mathrm{~h})$ :

$$
\begin{aligned}
& \mathrm{uuu} ; \mathrm{u}+\frac{1}{2}, \frac{1}{2}-\mathrm{u}, \overline{\mathrm{u}} ; \overline{\mathrm{u}}, \mathrm{u}+\frac{1}{2}, \frac{1}{2}-\mathrm{u} ; \frac{1}{2}-\mathrm{u}, \overline{\mathrm{u}}, \mathrm{u}+\frac{1}{2} ; \\
& \text { ūūū; } \frac{1}{2}-\mathrm{u}, \mathrm{u}+\frac{1}{2}, \mathrm{u} ; \mathrm{u}, \frac{1}{2}-\mathrm{u}, \mathrm{u}+\frac{1}{2} ; \mathrm{u}+\frac{1}{2}, \mathrm{u}, \frac{1}{2}-\mathrm{u} ;
\end{aligned}
$$

Four equivalent positions:

4 (b): $000 ; 0 \frac{1}{2} \frac{1}{2} ; \frac{1}{2} \frac{1}{2} 0 ; \frac{1}{2} 0 \frac{1}{2}$.

$4\left(\right.$ c) : $\frac{1}{2} \frac{1}{2} \frac{1}{2} ; 0 \frac{1}{2} 00 ; 00 \frac{1}{2} ; 0 \frac{1}{2} 0$.

It is readily seen that by assigning to $u$ the value $1 / 4$, both the nickel atoms and the nitrate nitrogen atoms will occupy identically the same positions that they have in the arrangement deducible from $\mathrm{T}_{\mathrm{h}}{ }^{3}$; they consequently will contribute nothing to first order reflections from planes having other than all odd indices. By an appropriate equating of the coefficients in the intensity expressions for the most general positions of equivalent atoms, all of the particular values of $x, y$, and $z$ which will permit of first order reflections from all odd planes can be found. These prove to be identical with the two special cases of 24 equivalent positions which are derivable from the space group $\mathrm{T}_{\mathrm{h}}{ }^{3}$. They consequently introduce no new possibilities.

Two alternatives are presented. One consists in taking the diffraction data at their face value and assigning $\mathrm{Ni}\left(\mathrm{NO}_{3}\right)_{2} .6 \mathrm{NH}_{3}$ to the space group $\mathrm{T}_{\mathrm{h}}{ }^{3}$ in view of the complete absence of first order reflections except from all odd planes; but it has been pointed out that such an arrangement of the atoms destroys the identity of the nitrate group by its equal association of 6 oxygen atoms with each nitrogen atom. The other alternative is to assume that first order reflections from planes having even indices really exist, but with an intensity too faint to be detected in the Laue photographs. This crystal would then have the symmetry of the space group $\mathrm{T}_{\mathrm{h}}{ }^{6}$, with atomic positions either identical with or closely approximating those arising from $\mathrm{T}_{\mathrm{h}}{ }^{3}$. According to this arrangement the nickel atoms are to be found at the positions of $4(\mathrm{~b})$, the nitrate nitrogen atoms at $8(\mathrm{~h})$, and the ammonia nitrogen and the oxygen atoms in

7 The designations employed are those used in the writer's book entitled "An Analytical Representation of the Theory of Space Groups" shortly to be published by the Carnegie Institution of Washington. 
general positions. In order to satisfy the diffraction data, it is necessary that the value of $u$ for the nitrate nitrogen atoms be approximately $1 / 4$, and that the ammonia nitrogen atoms be either exactly in, or very close to, the positions designated by the coördinate values $v 00$, where $v$ is somewhat less than 0.25 . This is in accord with the relation between the nickel atom and its coördinated ammonia molecules as deduced from a study of the hexammoniate halides. The absence of strong first order reflections from other than all odd planes and of any observable dissymmetry in the photograph (such as is apparent in the photographs of crystals having pyritohedral symmetry) suggests that the oxygen atoms should not deviate far from the positions $1 / 4^{1} / 40$. The same procedure which showed that arrangements $24(\mathrm{a})$ and $24(\mathrm{c})$ arise from $\mathrm{T}_{\mathrm{h}}{ }^{6}$ indicates that, because $2 / 3$ of the atoms destructively interfere with one another in the first order, the intensity of reflection from an arrangement having the coördinate values $1 / 4^{1} / 4 v^{\prime}$ is particularly slight. It consequently becomes apparent that, if this second alternative is the correct one, the oxygen atoms cannot vary greatly from the positions designated by $1 / 4{ }^{1} / 4 v^{\prime}$. Calculations of intensity were carried out in the usual manner for different values of $u$ for the nitrate nitrogen atoms and of $v^{\prime}$ for the oxygen atoms; a comparison of such calculated intensities with those of planes actually appearing in the photographs indicates that both $u$ and $v^{\prime}$ may have a considerable range about the positions $u=1 / 4$ and $v^{\prime}=0$ without the amplitudes which they might contribute to first order reflections being significant.

There is good reason for believing that this second alternative is the correct one. Barium and strontium nitrates give crystals which upon the basis of the diffraction data they furnish have been assigned ${ }^{8}$ to the space group $\mathrm{T}_{\mathrm{h}}{ }^{6}$. In connection with the present work Laue photographs of both barium and strontium nitrate have been examined with results which agree with the previous ones in ascribing them to this space group. Diffraction data from crystals of $\mathrm{Zn}\left(\mathrm{BrO}_{3}\right)_{2} .6 \mathrm{H}_{2} \mathrm{O}$ and $\mathrm{Ni}\left(\mathrm{ClO}_{3}\right)_{2} \cdot 6 \mathrm{H}_{2} \mathrm{O}$, taken as substances similar in nature to the compound under investigation, ${ }^{9}$ agree in assigning both of these crystals definitely to this space group $\mathrm{T}_{\mathrm{h}}{ }^{6}$. It consequently seems probable that $\mathrm{Ni}\left(\mathrm{NO}_{3}\right)_{2} .6 \mathrm{NH}_{3}$ also has the symmetry of $T_{h}{ }^{6}$ with such values of the coördinate positions of its atoms as to make it approach closely to a truly face-centered structure. Accordingly, the positions of the atoms within a unit cell of this crystal are as follows: Nickel, arrangement 4 (b); Nitrogen (nitrate), 8(h), with a value of $u$, the variation of which from $u=1 / 4$ may be appreciable; Nitrogen (ammonia), general positions but with values of the coördinates equal or close to $\mathrm{x}=v, \mathrm{y}=0, \mathrm{z}=0$, where $v$ has a value somewhat less than 0.25 ; Oxygen, general positions but with values of the coördinates

${ }^{3}$ Nishikawa and Hudinuki, Proc. Tokyo Math. Phys. Soc., [2] 9, 197 (1917).

${ }^{9} \mathrm{~A}$ brief discussion of the structures of these crystals will be given in a later paper. 
probably close, to $\mathrm{x}=1 / 4, \mathrm{y}=1 / 4, \mathrm{z}=v^{\prime}$, where the variation of $v^{\prime}$ from zero cannot be ascertained with accuracy; Hydrogen, three sets of general positions which group the three hydrogen atoms about each ammonia nitrogen atom.

The structure thus assigned to $\mathrm{Ni}\left(\mathrm{NO}_{3}\right)_{2} \cdot 6 \mathrm{NH}_{3}$ is like that possessed by $\mathrm{NiCl}_{2}, 6 \mathrm{NH}_{3}$ with nitrate groups replacing the chlorine atoms, except that the centers of the nitrate groups may be displaced along the body diagonals of the unit much as are the sulfur atoms in pyrites.

Structures which are at all probable in a chemical sense and which involve an atomic equivalence different from that here assumed (such, for example, as those arising from the assumption that two of the oxygen atoms of a nitrate group are different from the third), cannot be made to conform with the experimental data. Neither is it apparent that anything is to be gained by assuming that 32 molecules, instead of 4, are contained within the unit cube.

\section{Summary}

From $\mathrm{X}$-ray spectrum measurements and space group reasoning it can be shown that the crystals formed on the addition of ammonia to a solution of nickel nitrate cannot have the composition usually ascribed to them. Careful chemical analysis proves them to be $\mathrm{Ni}\left(\mathrm{NO}_{3}\right)_{2} \cdot 6 \mathrm{NH}_{3}$. A study of the Laue photographs of these crystals by the generally applicable methods which use the theory of space groups indicates that they have a structure similar to that of the previously studied nickel hexammoniate halides with nitrate groups replacing the halogen atoms, and the ammonia groups related to the nickel atoms in the same manner in both compounds. The positions of the atoms of the nitrate groups cannot, however, be determined with great accuracy. Both the symmetry characteristics and the diffraction data permit the same kind of displacement of the nitrate nitrogen atoms as is experienced by the sulfur atoms in pyrites. The length of the side of the unit cube has been determined as $10.96 \AA$. U.

Pasadena, CALIFornia 